\title{
VIBRATION REDUCTION DESIGN WITH HYBRID STRUCTURES AND TOPOLOGY OPTIMIZATION
}

\author{
Fali Huo ${ }^{1}$ \\ Deqing Yang ${ }^{2}$ \\ Yinzhi Zhao' \\ ${ }^{1}$ School of Naval Architecture \& Ocean Engineering, Jiangsu University of Science and Technology, \\ Zhenjiang, Jiangsu, 212003, China \\ ${ }^{2}$ School of Naval Architecture, Ocean and Civil Engineering, Shanghai Jiao Tong University, Shanghai, \\ 200030, China
}

\begin{abstract}
The hybrid structures show excellent performance on vibration reduction for ship, aircraft and spacecraft designs. Meanwhile, the topology optimization is widely used for structure vibration reduction and weight control. The design of hybrid structures considering simultaneous materials selection and topology optimization are big challenges in theoretical study and engineering applications. In this paper, according to the proposed laminate component method (LCM) and solid isotropic microstructure with penalty (SIMP) method, the mathematical formulations are presented for concurrent materials selection and topology optimizations of hybrid structures. Thickness distributions of the plies in laminate components are defined as materials selection design variables by LCM method. Relative densities of elements in the components are defined as topology design variables by SIMP method. Design examples of hybrid 3-bar truss structures and hybrid floating raft with vibration reduction requirements verified the effectiveness of the presented optimization models.
\end{abstract}

Keywords: hybrid structure; vibration reduction; materials selection; topology optimization

\section{INTRODUCTION}

The vibration reduction plays important role in ship, aircraft and spacecraft designs. Hybrid structure is widely used to reduce vibration and control weight in ship, aircraft and spacecraft design for mechanical behavior, the inelastic damping behavior, and strength of hybrid structure, presently. Meanwhile, the topology optimization is the better method for vibration reduction and weight control.

In present study focus on optimal design methods for hybrid structure considering vibration reduction. Yang (2012) proposed a laminate component method (LCM) on modeling of hybrid structure for materials selection (type and size) design. By introducing the concept of laminate component, materials selection optimization design of hybrid structure is formulated as a size or topology optimization problem with all materials for selection within one structural analysis model. In study of structure design methods, mechanical behavior, the inelastic damping behavior, and strength of metal-hybrid structures are investigated (Hidde 1992, Asundi 1997, Kawai 1998, Botelhoa 2006). Blasques (2012) presents a novel framework for simultaneous optimization design of topology and laminate properties of laminated composite beam cross sections. The majority of the hull structures are manufactured by metal materials which can decrease the costs; and some important components are fabricated by composites materials which can decrease structure weight and vibration levels (Barsoum 2003, Cao 2007). The design of metal-composite hybrid structure involves simultaneous determinations on materials selection, topology, geometry, and components dimensions. 
In addition, structural dynamic performance like vibration levels and eigenfrequency must be taken into account for the purpose of vibration and noise reduction. Rahul (2006) dealt with optimization of hybrid fiber reinforced plastic laminated plates subjected to impact loading, Finite element method (FEM) and genetic algorithm (GA) have been used to obtain optimum laminate in terms of minimizing the cost, weight of graphite/epoxy-aramid/epoxy hybrid laminates while maximizing the strength.

The topology optimization for vibration reduction and weight control has been widely investigated. Sigmund (1999) suggested topology optimization procedure as a tool for smart materials design and discussed two applications in composite structures. Kravanja (2005) studied the simultaneous topology and size optimization of mechanical structures by the Mixed Integer Nonlinear Programming (MINLP) approach, and general multilevel MINLP formulations for mechanical superstructure were presented. Sun (2011) dealt with topology optimization of composite structure using Bi-directional Evolutional Structural Optimization (BESO) method. Stress concentration in composite structure can be reduced by BESO method and geometry of structure is easy to fabricate by techniques currently available. Coelho (2011) developed a computational procedure for two-scale topology optimization problem using parallel computing techniques, the material properties were designed in micro and macro scale respectively. Lee (2012) proposed an approach for topology optimization of structures under design-dependent pressure loading. Cherkaev (2012) introduced a new type of optimal isotropic structure for multi-material composites. Rakshit (2008) explored simultaneous geometry design and material selection for statically determinate trusses with continuous optimization model, and the available materials for selection were put in a database with design index along with the corresponding best geometry.

However, investigations of vibration reduction and weight control design on simultaneous by hybrid structure and topology optimization design are very scarce. One challenge in this problem is the establishment of a unified structural analysis and optimization model for different settings of materials selection and components topology distributions during solving iterations. The other challenge is the definitions of materials selection design variables and topology design variables in one optimization model, these design variables are all discrete variables in nature. In this paper, by applying the proposed laminate component method (Yang, 2012) and SIMP method, the mentioned challenges are attempted. The mathematical formulations for concurrent materials selection and topology optimization of hybrid structure are proposed with respect to vibration reduction constraints. Typical metal-composite hybrid structures optimization examples are performed to demonstrate the effectiveness of the proposed models.

\section{LAMINATE COMPONENT METHOD FOR HYBRID STRUCTURE OPTIMIZATION}

Laminate component method (LCM) was firstly applied in materials selection (type and size) optimization design of hybrid structure (Yang 2012). Based on LCM method, materials selection optimization design can be formulated as a continuous optimization problem to avoid the conventional discrete optimization model depending on materials database and materials design index method. The laminate component method consists of three main steps.

1) First, replace the design components in hybrid structure with laminated composite components that each ply fabricated by different materials for selection.

2) Second, discretize and construct finite element model of the hybrid structure.

3) Finally, define thickness of each ply or materials topology distribution of each ply in laminated composite design components as materials selection design variables, establish optimization model with vibration reduction constraints and complete optimization.

An engineering design example of hybrid floating raft with LCM method is shown in Fig.1. The laminate component method firstly assumes each design component (No.1 to No.7)
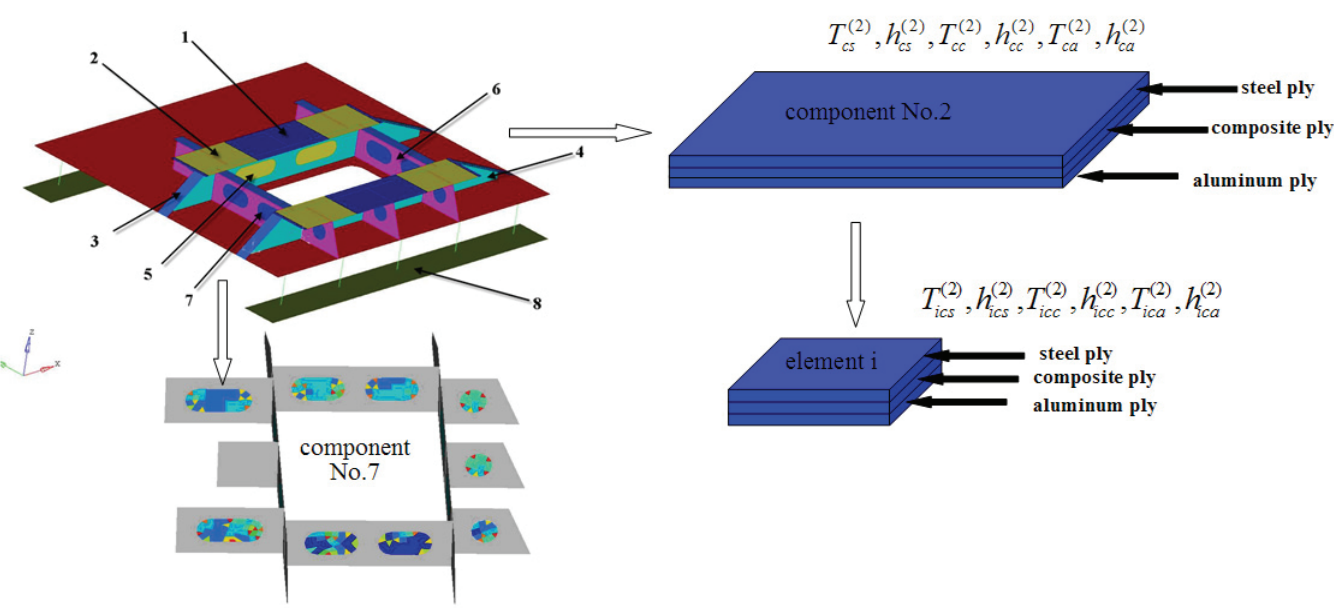

Fig. 1 Design domains and laminate components in continuum hybrid structure 
is made of laminate plate with available materials for selection as each ply - steel ply, composite materials ply and aluminum ply (as shown in component No.2 in Fig.1), then finite element model of hybrid structure is constructed. Finally thickness of each ply is defined as materials selection design variables, optimization model is established and solved. Though there are four materials selection optimization models according to LCM method, in which materials elastic modulus, thickness of ply, and materials topology distribution are defined as design variables respectively, the use of thickness as materials selection design variables is the reasonable choice when topology optimization design is also required. Model II can avoid the discreteness and complexity of the structural analysis model due to the variation of materials elastic modulus and materials topology distribution. As a continuum structure, hybrid floating raft is composed by web plates, rib plates, flange plates and panels. These plates (design components) are easily replaced by laminated composite plates with LCM method.

\section{SIMP METHOD FOR STRUCTURAL TOPOLOGY OPTIMIZATION}

Many topology optimization methods like homogenization method (Bendsøe 1989, 2003), density method, evolutionary structural optimization method (Xie 1997) and ICM method (Sui 1998) have been investigated and applied in engineering. SIMP method is a widely used simple topology optimization approach (Zhou 1991) combined the finite element method and density method. A topology optimization problem based on SIMP where the objective is to minimize compliance can be written as

$$
\begin{array}{cc}
\operatorname{Min}_{\mathbf{X}} & C(\mathbf{X})=\mathbf{U}^{T} \mathbf{K} \mathbf{U}=\sum_{e=1}^{N}\left(x_{e}\right)^{p} \mathbf{u}_{e}^{T} \mathbf{k}_{e} \mathbf{u}_{e} \\
\text { s.t. } & \frac{V(\mathbf{X})}{V_{0}} \leq f \\
& \mathbf{K U}=\mathbf{F} \\
& 0<x_{\min } \leq x_{e} \leq 1
\end{array}
$$

where $\mathrm{U}$ and $\mathrm{F}$ are the global displacement and force vectors, respectively, $\mathrm{K}$ is the global stiffness matrix, $\mathbf{u}_{e}$ and $\mathbf{k}_{e}$ are the element displacement vector and stiffness matrix, respectively, $\mathbf{X}=\left[x_{1}, x_{2}, \cdots, x_{e}, \cdots x_{N}\right]^{T}$ is the vector of design variables of relative densities of elements, $X_{\min }$ is a vector of minimum relative densities (non-zero to avoid singularity), $\mathrm{N}$ is the number of elements used to discretize the design domain, $\mathrm{p}$ is the penalization power (typically $\mathrm{p}=3$ ), $V(\mathrm{X})$ and $V_{0}$ is the material volume and design domain volume, respectively and $f$ is the prescribed volume fraction.

In this paper, SIMP method is used to define the topological design variables of elements in each laminate component or components without materials selection design requirement. For the elements with materials selection design requirement, each element consists of multiple material plies according to laminate component method, and $X_{e}$ is the topological value of the eth laminate element. $X_{e}$ has no connection with materials selection design, and it only decides the existence of the element. For the elements without materials selection design requirement in components, each element consists of isotropic material, $X_{e}$ denotes the existence of the element.

\section{HYBRID STRUCTURE DESIGN FOR VIBRATION REDUCTION BY MATERIALS SELECTION AND TOPOLOGY OPTIMIZATION ON SIMULTANEOUS}

\section{THE MATHEMATICAL MODEL OF HYBRID STRUCTURE DESIGN}

By applying LCM method to deal with materials selection, and applying SIMP method to define the component topology in hybrid structure, the concurrent optimization model for materials selection and topology design is formulated as Eq.2. The weight of hybrid structure is considered as the objective function with acceleration vibration level differences, stresses and displacements on designated points and elements as constraints.

$$
\begin{gathered}
\text { Find } \begin{array}{c}
\mathbf{T}_{s}=\left[t_{1 s}, t_{2 s}, \cdots, t_{m s}, t_{m+1 s}, \cdots, t_{n s}\right]^{T} \\
\mathbf{T}_{c}=\left[t_{1 c}, t_{2 c}, \cdots, t_{i c}, \cdots, t_{m c}\right]^{T} \\
\tilde{\mathbf{X}}_{t}=\left[\mathbf{X}_{1}, \mathbf{X}_{2}, \cdots, \mathbf{X}_{i}, \cdots, \mathbf{X}_{n}\right]^{T} \\
\text { Min Weight }=\sum_{i=1}^{m} \sum_{t=1}^{T_{i T}}\left(t_{i c} \cdot \rho_{c}+t_{i s} \cdot \rho_{s}\right) \cdot s e_{i t} \cdot x_{i t}+\sum_{i=1}^{m} \sum_{t=T_{i T}+1}^{T_{i}}\left(t_{i c} \cdot \rho_{c}+t_{i s} \cdot \rho_{s}\right) \cdot s e_{i t}+ \\
\sum_{i=m+1}^{n} \sum_{t=1}^{T_{i T}} t_{i s} \cdot \rho_{s} \cdot s e_{i t} \cdot x_{i t}+\sum_{i=m+1 t=T_{i T}+1}^{n} \sum_{i s}^{T_{i}} t_{s} \cdot \rho_{s} \cdot s e_{i t} \\
\sigma_{e}^{L} \leq \sigma_{e k}\left[\mathbf{T}_{s}, \mathbf{T}_{c}, \tilde{\mathbf{X}}_{t}\right] \leq \sigma_{e}^{U} \\
\delta_{p k}\left[\mathbf{T}_{s}, \mathbf{T}_{c}, \tilde{\mathbf{X}}_{t}\right] \leq \bar{\delta}_{p} \\
a_{A j}^{\max } \leq a_{A}^{U} \\
a_{B j}^{\max } \leq a_{B}^{U} \\
10^{L, 20}-\varepsilon \leq a_{A j}^{\max } / a_{B j}^{\max } \leq 10^{L, / 20}+\varepsilon \\
f^{L} \leq j \leq f^{U} \\
t_{i c}=s c a \cdot t_{i s} \\
t_{i s}^{L} \leq t_{i s} \leq t_{i s}^{U} \\
\mathbf{X}_{i}=\left[x_{i 1}, x_{i 2}, \cdots, x_{i t}, \cdots, x_{i T_{i T}}\right]^{T} \\
0<x_{\min } \leq x_{i t} \leq 1 \\
i=1,2, \cdots, n ; e=1,2, \cdots, E ; k=1,2, \cdots, K \\
p=1,2, \cdots, P ; t=1,2, \cdots, T_{i T}
\end{array}
\end{gathered}
$$

The meanings of design variables and constraints are listed in Nomenclature. $n \geq m$ means some components no materials type selection design requirements.

Based on the proposed model, a single unified structural analysis and optimization model is implemented during 
the optimization procedure. The variation of topology and materials types during optimization iteration can be accounted in a single structural analysis model by changing thickness and relative density of each element. Then the analysis results from this single structural model are used in the single proposed optimization model as Eq.2. Optimization model and structural analysis model are unified in one model.

$$
\begin{aligned}
& T_{i \mathrm{P}}=T_{i \mathrm{~s}}+T_{i \mathrm{c}} \\
& T_{i s}=\left[1+f\left(t_{i s}\right)\right] / 2 \cdot t_{i s}+t_{s \min } \\
& T_{i c}=\left[1-f\left(t_{i s}\right)\right] / 2 \cdot t_{i s} \cdot s c a+t_{c \min } \\
& f\left(t_{i s}\right)=\operatorname{sgn}\left[\sin \left(1000 \cdot t_{i s} \cdot \pi\right)\right]
\end{aligned}
$$

$T_{\dot{\mathrm{s}}}$ is the equivalent thickness of steel layer in the ith component after transformation, and the $T_{i c}$ is the equivalent thickness of composite material layer in the ith component after transformation. sgn is the sign function. The values of $f\left(t_{i s}\right)$. $\mathrm{k}$ is a non-negative integer. $t_{s \min }$ and $t_{c \min }$ are minimal thickness for steel layer and composite material layer respectively to avoid element stiffness matrix singularity. The numbers of design variables for topology, size and material selection optimization and the element numbers in FEM model in the presented concurrent optimization are large, therefore a long computation time will cost to get

$$
\begin{aligned}
& \text { Find } \quad \mathbf{T}_{s}=\left[t_{1 s}, t_{2 s}, \cdots, t_{m s}, t_{m+1 s}, \cdots, t_{n s}\right]^{T} \\
& \mathbf{T}_{c}=\left[t_{1 c}, t_{2 c}, \cdots, t_{i c}, \cdots, T_{m c}\right]^{T} \\
& \tilde{\mathbf{X}}_{t}=\left[\mathbf{X}_{1}, \mathbf{X}_{2}, \cdots, \mathbf{X}_{i}, \cdots, \mathbf{X}_{m}\right]^{T} \\
& \text { Min Weight }=\sum_{i=1}^{m} \sum_{t=1}^{T_{T r}}\left(T_{i c} \cdot \rho_{c}+T_{i s} \cdot \rho_{s}\right) \cdot s e_{i t} \cdot x_{i t}+\sum_{i=1}^{m} \sum_{t=T_{T i}+1}^{T_{i}}\left(T_{i c} \cdot \rho_{c}+T_{i s} \cdot \rho_{s}\right) \cdot s e_{i t}+ \\
& \sum_{i=m+1}^{n} \sum_{t=1}^{T_{i T}} t_{i s} \cdot \rho_{s} \cdot s e_{i t} \cdot x_{i t}+\sum_{i=m+1}^{n} \sum_{t=T_{T T}+1}^{T_{i}} t_{i s} \cdot \rho_{s} \cdot s e_{i t} \\
& \text { s.t. } \quad \sigma_{e}^{L} \leq \sigma_{e k}\left[\mathbf{T}_{s}, \mathbf{T}_{c}, \tilde{\mathbf{X}}_{t}\right] \leq \sigma_{e}^{U} \\
& \delta_{p k}\left[\mathbf{T}_{s}, \mathbf{T}_{c}, \tilde{\mathbf{X}}_{t}\right] \leq \bar{\delta}_{p} \\
& a_{A j}^{\max } \leq a_{A}^{U} \\
& a_{B j}^{\max } \leq a_{B}^{U} \\
& 10^{L_{r} / 20}-\varepsilon \leq a_{A j}^{\max } / a_{B j}^{\max } \leq 10^{L_{r} / 20}+\varepsilon \\
& f^{L} \leq j \leq f^{U} \\
& t_{i c}=s c a \cdot t_{i s} \\
& t_{i s}^{L} \leq t_{i s} \leq t_{i s}^{U} \\
& \mathbf{X}_{i}=\left[x_{i 1}, x_{i 2}, \cdots, x_{i t}, \cdots, x_{i T_{i T}}\right]^{T} \\
& 0<x_{\min } \leq x_{i t} \leq 1 \\
& T_{i p}=T_{i s}+T_{i c} \\
& T_{i s}=\left[1+f\left(t_{i s}\right)\right] / 2 \cdot t_{i s}+t_{s \min } \\
& T_{i c}=\left[1-f\left(t_{i s}\right)\right] / 2 \cdot t_{i s} \cdot s c a+t_{c \min } \\
& f\left(t_{i s}\right)=\operatorname{sgn}\left[\sin \left(1000 \cdot t_{i s} \cdot \pi\right)\right] \\
& i=1,2, \cdots, m ; e=1,2, \cdots, E ; k=1,2, \cdots, K \text {; } \\
& t=1,2, \cdots, T_{i T} ; p=1,2, \cdots, P
\end{aligned}
$$

one optimization result(in this example, more than twenty hours for an optimal results). For the larger structure with more design variables and elements, advanced computer or workstation, and more effective optimization algorithm should be considered.

\begin{tabular}{|c|c|c|}
\hline \multirow{3}{*}{ steel } & Young's modulus & $210 \mathrm{GPa}$ \\
\hline & Poisson's ratio & 0.3 \\
\hline & density & $7850 \mathrm{~kg} / \mathrm{m}^{3}$ \\
\hline \multirow{11}{*}{$\begin{array}{c}\text { fiber } \\
\text { reinforced } \\
\text { composite }\end{array}$} & \multirow{2}{*}{ Young's modulus } & $\mathrm{E}_{11}=27285.7 \mathrm{MP} a$ \\
\hline & & $\mathrm{E}_{22}=26142.8 \mathrm{MPa}$ \\
\hline & \multirow{3}{*}{ shear modulus } & $\mathrm{G}_{12}=9242.9 \mathrm{MPa}$ \\
\hline & & $\mathrm{G}_{23}=9242.9 \mathrm{MPa}$ \\
\hline & & $\mathrm{G}_{13}=9242.9 \mathrm{MPa}$ \\
\hline & Poisson's ratio & 0.14 \\
\hline & \multirow{3}{*}{ damping coefficient } & $\eta_{11}=0.0729$ \\
\hline & & $\eta_{22}=0.0715$ \\
\hline & & $\eta_{12}=\eta_{23}=\eta_{13}=0.1068$ \\
\hline & density & $1600 \mathrm{~kg} / \mathrm{m}^{3}$ \\
\hline & ply angles & {$\left[90^{\circ} / 0^{\circ}\right]_{\mathrm{s}}$} \\
\hline
\end{tabular}

The mathematical formulations after transformation are presented in Eqn.3.

The meanings of design variables are same as Eqn.2.

\section{ILLUSTRATING METHOD BY EXAMPLE}

\section{STEEL-COMPOSITE MATERIAL HYBRID 3-BAR TRUSS STRUCTURE DESIGN}

The method of materials selection and topology optimization on simultaneous through combining the LCM method and SIMC method for Hybrid structure design is illustrated by a 3-bar truss structure as an example. Fig. 2 shows the dimensions and connection of 3-bar truss. Available materials for selection are steel and fiber reinforced composite. Thickness of steel_plate is $15 \mathrm{~mm}$; girder is made of $100 \times 50 \times 10$ steel L-bar. The materials parameters for selection are steel and composite material in Table 1. Boundary conditions, reference points and loading conditions are shown in Fig. 3. There is a $454 \mathrm{~kg}$ concentrated mass at point A. A $100 \mathrm{~N}$ vertical force acts on point $\mathrm{A}$ in $\mathrm{Z}$ direction with frequency range $1-100 \mathrm{~Hz}$. The modal damping loss factor for structural frequency response is $2 \%$. Constraints for optimization design are: (1) AVLD $>5 \mathrm{~dB}$ at point A, B and E. (2) Allowable displacement at point $\mathrm{C}$ is $1 \mathrm{~mm}$. (3) Maximum acceleration amplitude for the reference points is $0.5 \mathrm{~g}$.

Table 1 Materials parameters 
Table 2 Design variables and objective value

\begin{tabular}{|c|c|c|c|c|c|}
\hline $\begin{array}{l}\dot{0} \\
\dot{z} \\
\dot{\tilde{n}}\end{array}$ & 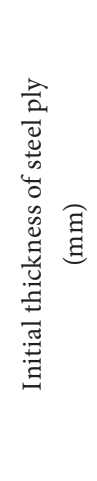 & 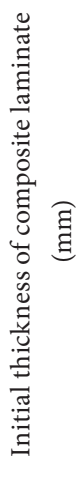 & 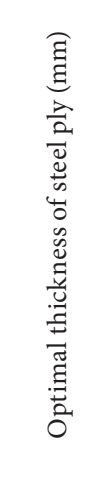 & 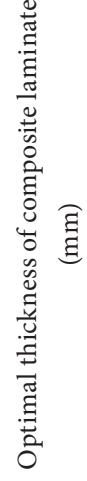 & 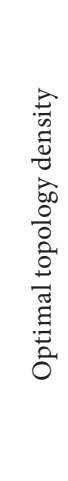 \\
\hline Comp_1 & 20 & 0.03 & 0.005 & 46.632 & 0.435 \\
\hline Comp_2 & 20 & 0.03 & 0.005 & 46.632 & 0.385 \\
\hline Comp_3 & 20 & 0.03 & 19.1 & 0.03 & 0.062 \\
\hline $\begin{array}{l}\text { Objective } \\
\text { function }\end{array}$ & $\begin{array}{c}\text { Initial } \\
\text { weight } \\
(\mathrm{kg})\end{array}$ & 60.5 & $\begin{array}{c}\text { Optimal } \\
\text { result } \\
(\mathrm{kg})\end{array}$ & 33.7 & -- \\
\hline
\end{tabular}

Optimization results are shown in Table 2. It shows that the weight of truss decreased from $60.5 \mathrm{~kg}$ to $33.7 \mathrm{~kg}$. Fig. 4 shows topological densities of bars after optimization. Since density value for bar Comp_3 is less than 0.062 , it is deleted in final structural design shown in Fig.5. In final optimal topology of structure, two bars are kept, in which bar Comp_1 and bar Comp_2 are made of composite materials.

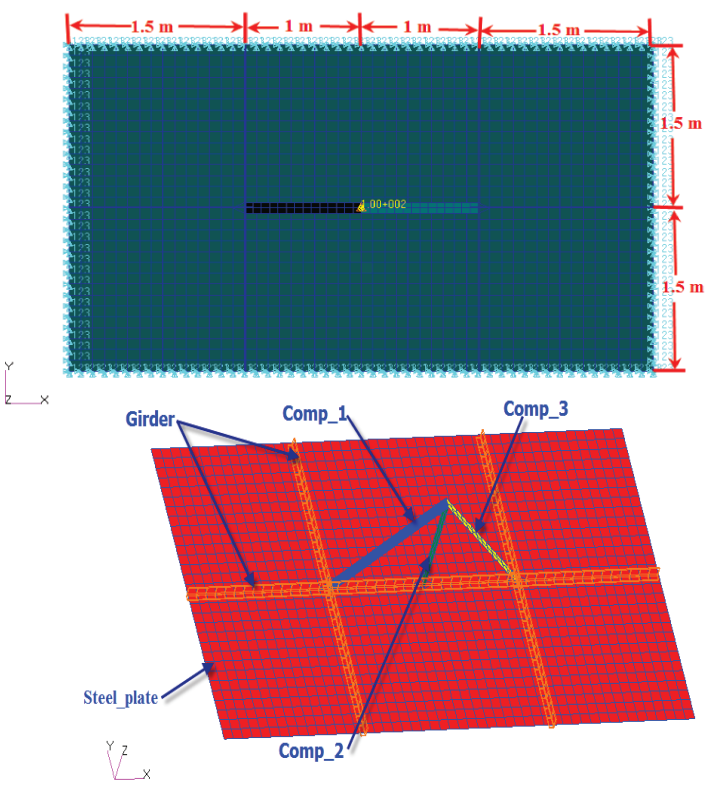

Fig.2 Dimensions of 3-bar truss

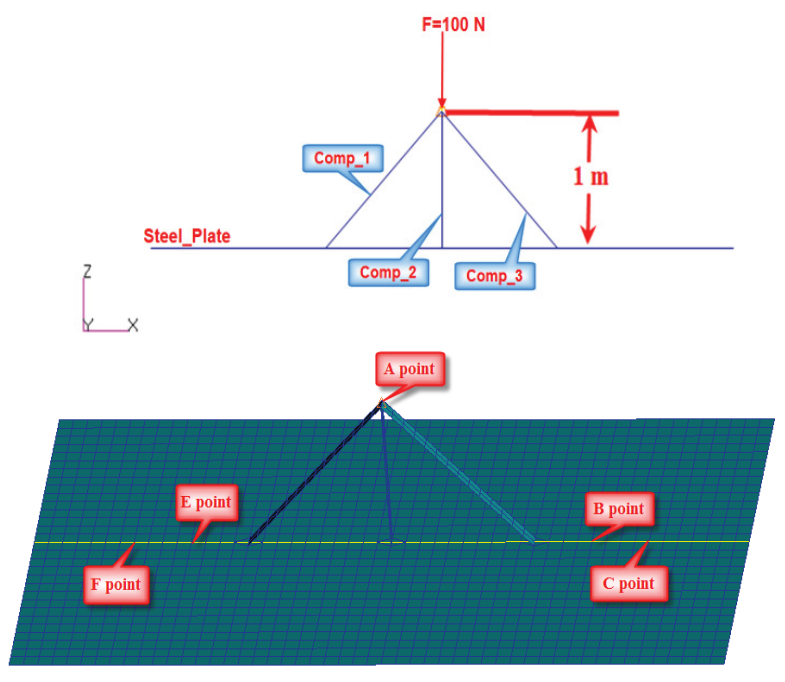

Fig.3 Boundary and loading conditions

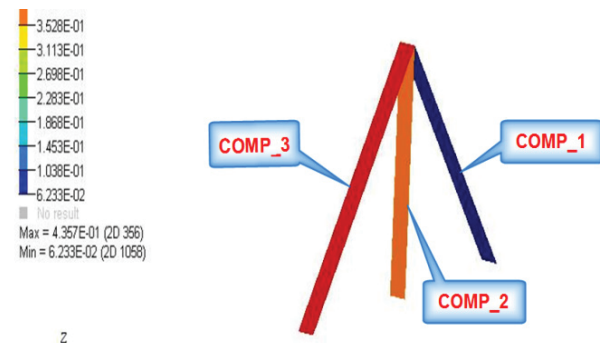

$\int_{x \rightarrow y}^{2}$

Fig.4 Topological densities of bars

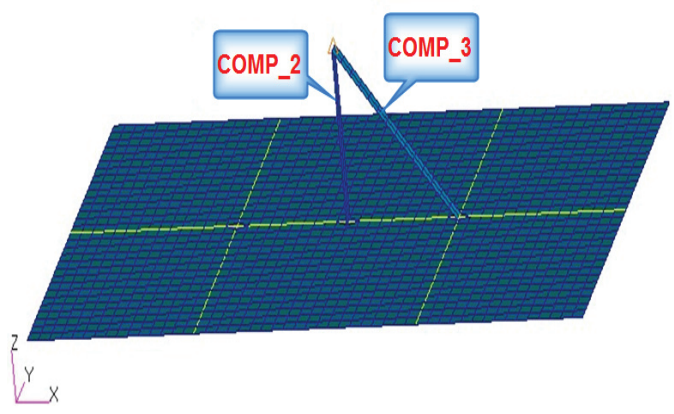

Fig.5 Final topology of 3-bar truss

\section{STEEL-COMPOSITE MATERIAL HYBRID FLOATING RAFT DESIGN}

A typical engineering floating raft is used for illustrating the feasibility of above method. The structure of the floating raft (Yang 2012) is shown in Fig.1 and Fig.6; definitions of each component are listed in Table 4. 
Table 3 Parameters of the floating raft

\begin{tabular}{|l|c|}
\hline flexible pipes and concentrated mass & $80 \mathrm{~kg}$ \\
\hline compressor & $294 \mathrm{~kg}$ \\
\hline refrigeration pump & $65 \mathrm{~kg}$ \\
\hline dimensions of the floating raft & $900 \mathrm{~mm} / 800 \mathrm{~mm} / 210 \mathrm{~mm}$ \\
\hline vibration isolator & BE-60 \\
\hline
\end{tabular}

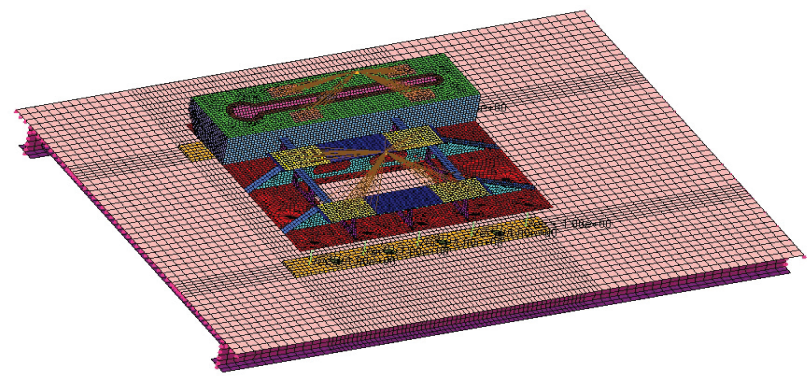

Fig.6 Finite element model of the floating raft

\section{The Model of hybrid floating raft}

The presented floating raft is a small scale model of special testing vessel in order to test the effect of vibration reduction optimization design. The joints between different components are assumed ideal. Parameters of the floating raft are shown in Table 3; the available materials for selection are steel and composite material in Table 1. Xiong (1996), and Xing (2005) investigated evaluation methods on vibration reduction of floating raft by finite element method and power flow method. $\mathrm{Yu}$ (2007) proposed a topology optimization model for the floating raft. The investigation results showed the effectiveness of finite element method and vibration level difference.

Fig. 6 shows the finite element model of the floating raft mounted on the bottom deck of ship. The effect of vibration reduction is evaluated by AVLD at the referenced points shown in Fig.7, $\mathrm{Aj}$ and $\mathrm{Cj}(\mathrm{j}=1,2, \ldots, 5)$ are top referenced points for isolators, $\mathrm{Bj}$ and $\mathrm{Dj}(\mathrm{j}=1,2, \ldots, 5)$ are bottom referenced points for isolators. The unit forces act on the center of compressor and refrigeration pump at vertical direction from $1 \mathrm{~Hz}$ to $1000 \mathrm{~Hz}$.

The design requirements: 1) Determine the material types for components No.1 to No.7, and the thickness of each component; 2) Topology optimization design for component No.5 and No.7; 3) Vibration reduction requirements: AVLD at the referenced points $>20 \mathrm{~dB}$ among $1 \mathrm{~Hz}$ and $1000 \mathrm{~Hz}$; 4) Maximum accelerations at the referenced points: $a_{(A m) j}^{\max } \leq 80 \mathrm{~mm}^{2}$ $a_{(\mathrm{Cm})_{p}}^{\max } \leq 80 \mathrm{mms}^{-2}$; 5) Maximum vertical displacement less than $1 / 300$ of the floating raft's length, which is equal to $6.7 \mathrm{~mm}$; 6) Stress constraints: $\sigma_{e} \leq 100 \mathrm{MPa}$, this can be satisfied by defining the maximum acceleration limits.

The upper and the lower bounds on thickness design variables are $20 \mathrm{~mm}$ and $4 \mathrm{~mm}$ except component No.8. The upper and the lower bounds on thickness for the component No. 8 are $60 \mathrm{~mm}$ and $6 \mathrm{~mm}$. The lower bound for thickness is to avoid structural buckling and yielding. According to the design requirements, the thickness of composite laminates components should be 2.5 times of the replaced steel plates (sca =2.5).

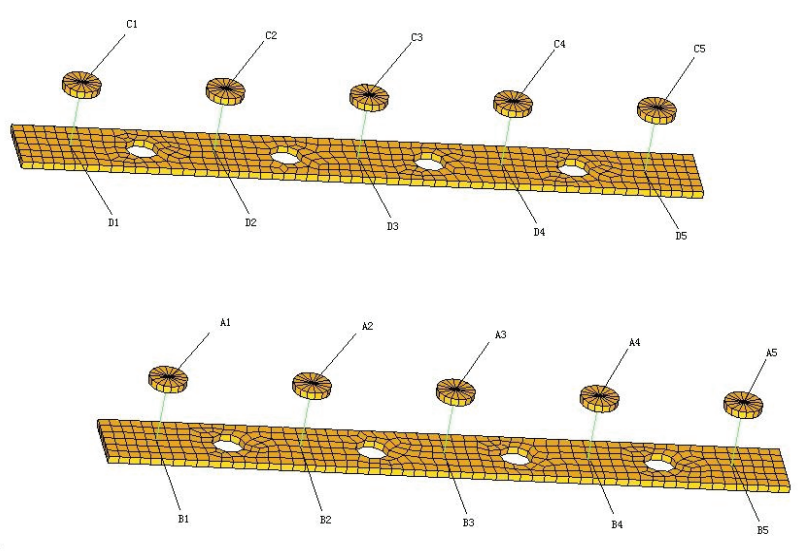

Fig.7 Locations of the reference points

Materials selection and topology optimization results on simultaneous

The results for the concurrent optimization of materials selection (type and size) and topology optimization are listed in Table 4 and Table 5 compared with Xie's results (2011) in which materials selection optimization are implemented considering vibration reduction constraints. Table 4 shows the comparisons of the objective function and the components thickness. Table 5 shows the comparison on the AVLD. Fig. 8 and Fig.9 show the results of element density after topology optimization. Fig.10 and Fig.11 are the re-designed structure according to the topology optimization results. Fig.12 presents the iterative history of the objective function. It can be seen the structure weight reduces from $46.426 \mathrm{~kg}$ to $25.940 \mathrm{~kg}$. Each constraint is satisfied and AVLD at some reference points are increased when materials of the web plates become composites. In the final hybrid structure, five components are made of composite materials which are quite different from the initial steel structure design.

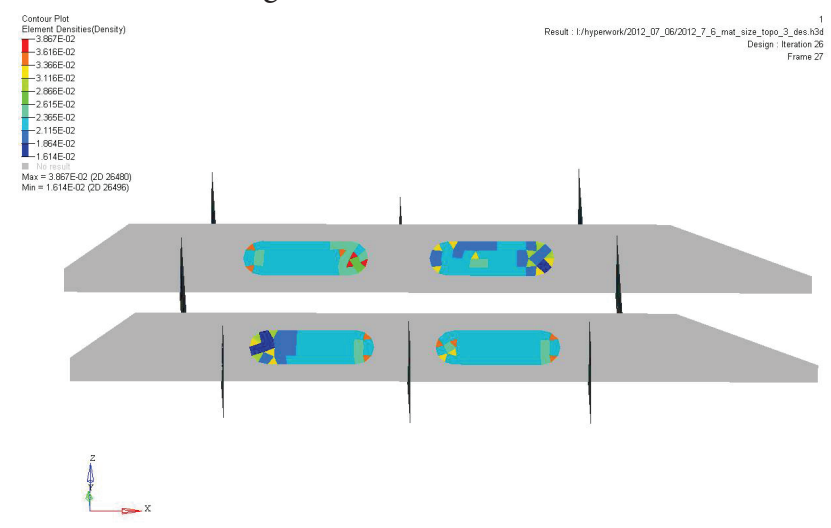

Fig.8 Topology optimization result for hlb-hole component 


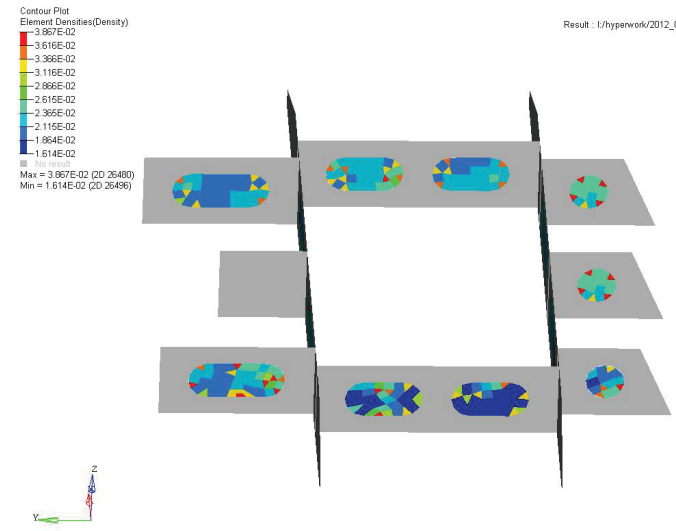

Fig.9 Topology optimization result for zlb-hole component

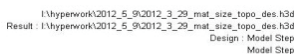

Fig.10 Re-design for hlb component

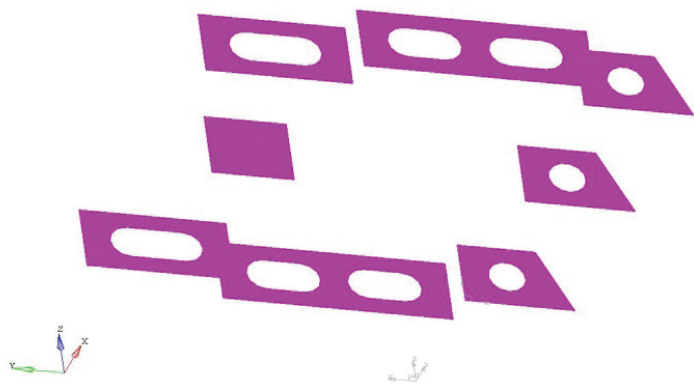

Fig.11 Re-design for zlb component

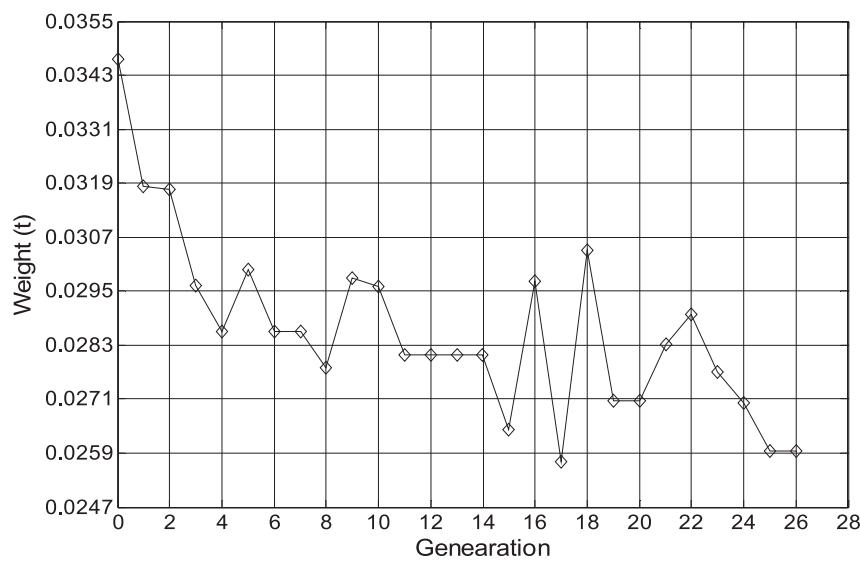

Fig.12 The iterative history of objective function

Table 5 values of $A V L D$ and acceleration on referenced points

\begin{tabular}{|c|c|c|c|c|c|c|c|}
\hline \multicolumn{2}{|c|}{$\begin{array}{c}\text { Reference point } \\
\text { No. }\end{array}$} & $a_{\nexists l}^{\max }$ & $a_{B h}^{\max }$ & $\begin{array}{l}\text { AVLD } \\
(\mathrm{dB})\end{array}$ & $a_{\overparen{a}}^{\max }$ & $a_{b b}^{\max }$ & $\begin{array}{l}\text { AVLD } \\
(\mathrm{dB})\end{array}$ \\
\hline \multirow{3}{*}{1} & Initial value & 73.00 & 5.45 & 22.54 & 74.19 & 5.51 & 22.58 \\
\hline & $\begin{array}{c}\text { Optimal value (Xie } \\
\text { 2011) }\end{array}$ & 70.25 & 4.25 & 24.37 & 73.40 & 4.37 & 24.51 \\
\hline & Optimal value & 67.41 & 4.23 & 24.05 & 71.48 & 4.39 & 24.23 \\
\hline \multirow{3}{*}{2} & Initial value & 69.05 & 2.74 & 28.04 & 69.42 & 2.75 & 28.05 \\
\hline & $\begin{array}{c}\text { Optimal value (Xie } \\
\text { 2011) }\end{array}$ & 66.48 & 2.64 & 28.01 & 68.89 & 2.68 & 28.21 \\
\hline & Optimal value & 64.10 & 2.56 & 27.97 & 67.41 & 2.60 & 28.28 \\
\hline \multirow{3}{*}{3} & Initial value & 64.20 & 5.09 & 22.02 & 64.76 & 5.12 & 22.04 \\
\hline & $\begin{array}{c}\text { Optimal value (Xie } \\
2011)\end{array}$ & 61.87 & 3.79 & 24.27 & 64.51 & 3.88 & 24.43 \\
\hline & Optimal value & 59.78 & 3.86 & 23.80 & 63.46 & 4.00 & 24.01 \\
\hline \multirow{3}{*}{4} & Initial value & 59.39 & 6.92 & 18.67 & 59.94 & 6.99 & 18.67 \\
\hline & $\begin{array}{c}\text { Optimal value (Xie } \\
\text { 2011) }\end{array}$ & 57.38 & 4.72 & 21.70 & 59.95 & 4.87 & 21.81 \\
\hline & Optimal value & 55.88 & 4.91 & 21.12 & 59.33 & 5.13 & 21.26 \\
\hline \multirow{3}{*}{5} & Initial value & 266.48 & 3.41 & 37.86 & 55.19 & 3.44 & 24.10 \\
\hline & $\begin{array}{c}\text { Optimal value (Xie } \\
\text { 2011) }\end{array}$ & 79.60 & 2.73 & 29.29 & 55.47 & 2.80 & 25.93 \\
\hline & Optimal value & 50.00 & 2.76 & 25.16 & 55.28 & 2.86 & 25.72 \\
\hline
\end{tabular}




\begin{tabular}{|c|c|c|c|c|c|c|c|}
\hline 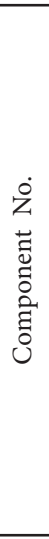 & 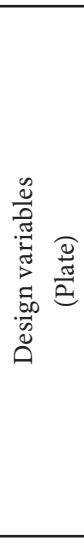 & 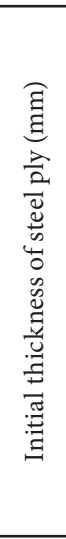 & 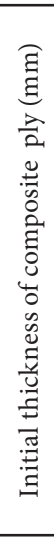 & 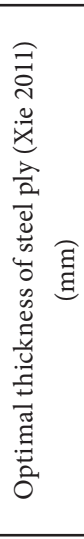 & 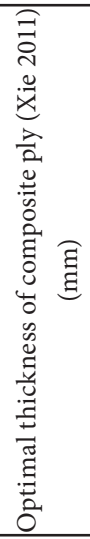 & 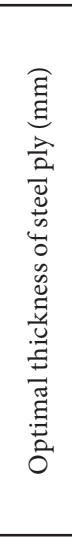 & 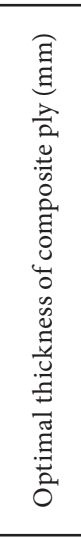 \\
\hline 1 & mb_1 & 10.01 & 0.03 & 9.9803 & 0.0492 & 4.687 & 0.030 \\
\hline 2 & mb_2 & 20.01 & 0.03 & 0.0164 & 49.9589 & 0.005 & 12.660 \\
\hline 3 & mb_3 & 6.01 & 0.03 & 5.9920 & 0.0200 & 0.005 & 11.514 \\
\hline 4 & zlb_1 & 6.01 & 0.03 & 0.0050 & 14.9876 & 0.005 & 11.754 \\
\hline 5 & zlb_hole & 6.01 & 0.03 & -- & -- & 4.657 & 0.030 \\
\hline 6 & hlb_1 & 6.01 & 0.03 & 0.0243 & 14.9393 & 0.005 & 12.006 \\
\hline 7 & hlb_hole & 6.01 & 0.03 & -- & -- & 0.005 & 12.120 \\
\hline 8 & squares & 16.00 & -- & 16.3988 & -- & 14.70 & -- \\
\hline 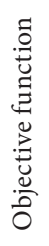 & 1 & 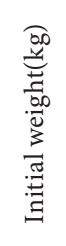 & \begin{tabular}{l} 
: \\
\multirow{H}{*}{} \\
ț
\end{tabular} & 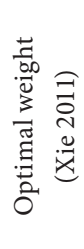 & $\begin{array}{l}\text { D } \\
+ \\
\dot{0} \\
\text { n. }\end{array}$ & 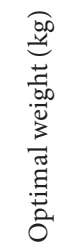 & $\begin{array}{l}\text { 우 } \\
\text { Lे } \\
\text { in }\end{array}$ \\
\hline
\end{tabular}

\section{CONCLUSIONS}

The hybrid structure optimization design for materials selection (type and size) and topology considering vibration reduction has been implemented. Combining LCM and SIMP method, a concurrent materials selection and topology optimization model for hybrid metal-composite structures is established. Typical steel-composite hybrid floating raft and hybrid truss are optimized for vibration reduction by the proposed model. The contributions of the research work and observations are summarized as follows:

1. By the proposed approach, the design variables for topology and materials selection can be combined in a unified structural finite element analysis model, in particular, combined in each element of the design domain of the hybrid structure.

2. The optimization results also verified the effectiveness of the use of composite materials in vibration reduction design. The initial all metal-made structure of 3-bar truss and floating raft become hybrid structure after optimization design with most of components made of composite materials.

\section{ACKNOWLEDGMENT}

The work described in this paper is supported in part by grants from the National Natural Science Foundation of China (Nos. 11072149). The authors are grateful for these financial supports.

\section{REFERENCES}

1. Asundi A., Choi A. (1997) "Fiber metal laminates: an advanced material for future aircraft." Journal of Materials processing technology. 63, 384-94.

2. Barsoum R. (2003). “The best of both worlds: hybrid ship hulls use composites and steel.” Amptiac Quart. 7(3), $55-61$.

3. BendsØe M., Sigmund O. (2003). “Topology optimization: theory, methods, and applications.” Springer Verlag; 2nd; ISBN 3540429921.

4. BendsØe M. (1989). "Optimal shape design as a material distribution problem.” Struct. Optim, 1:193-202.

5. Blasques J. P., Stolpe M. (2012). "Multi-material topology optimization of laminated composite beam cross sections." Composite Structures. 94, 3278-3289.

6. Botelho E.C., Campos A.N., Barros E. D. (2006). "Damping behavior of continuous fiber/metal composite materials by the free vibration method." Composites Part B: engineering. $37,255-263$.

7. Cao J., Grenestedt J., Maroun W. (2007). “Steel truss/ composite skin hybrid ship hull. Part I: Design and analysis." Composites Part A-Applied Science and Manufacturing. 38(7), 1755-1762.

8. Cherkaev A. (2012). "Optimal three-material wheel assemblage of conducting and elastic composites." International Journal of Engineering Science. 59, 27-39.

9. Coelho P. G., Cardoso J. B ., Fernandes P. R., etc. (2011). "Parallel computing techniques applied to the simultaneous design of structure and material." Advances in Engineering Software. 42, 219-227. 
10. Hidde J., Herakovich C. (1992). "Inelastic response of hybrid composite laminates." Journal of Composite Materials. 26, 2-19.

11. Kawai M., Morishita M., Tomura S. (1998). "Inelastic behavior and strength offiber-metal hybrid composite." International journal of Mechanical Sciences. 40, 183-198.

12. Kravanja S., Siliha S., Kravanja Z. (2005). “The multilevel MINLP optimization approach to structural synthesis: the simultaneous topology, material, standard and rounded dimension optimization." Advances in Engineering Software. 36, 568-583

13. Lee E., Martins J. R. R. A. (2012). "Structural topology optimization with design-dependent pressure loads." Computer Methods in Applied Mechanics and engineering. 233, 40-48.

14. Pan J., Wang D. Y. (2006) "Truss topology optimization under dynamic constraints.” Vibration and Shock. 25 (4), 8-12.

15. Rahul, G. S., Chakraborty D., Dutta A. (2006). "Multiobjective optimization of hybrid laminates subjected to transverse impact." Composite Structures. 73, 360-369.

16. Rakshit S., Ananthasuresh, G. K. (2008). "Simultaneous material selection and geometry design of statically determinate trusses using continuous optimization." Structure and Multidisciplinary Optimization. 35, $55-68$.

17. Sigmund O., Torquato A. S. (1999). "Design of smart composite materials using topology optimization.” Smart Material \& Structures. 8, 365-379.

18. Sui Y. K., Yang D. Q. (1998). “A new method for structural topological optimization based on the concept of independent continuous variables and smooth model." Acta Mechanica Sinica (English Edition). 18(2), 179-185.

19. Sun X., Yang F., Xie J., Huang Y. M., Zuo X. (2011). "Topology Optimization of Composite Structure Using Bi-Directional Evolutionary Structural Optimization Method." Procedia Engineering. 14, 2980-2985.

20. Xie X. L. (2011). "Key technologies on design and analysis of deepsea ROV and hybrid structures". Master Degree Thesis, Shanghai. Shanghai Jiao Tong University.

21. Xie Y. M., Steven G P. (1997). “Evolutionary structural optimization.” Berlin, Heidelberg, New York: Springer.

22. Xing X. L., Wang M. Q., Song D. (2005). "Study on vibration characteristic of flexible basement floating raft vibration-isolation system.” Mechanical Science and Technology. 2005-07.

23. Xiong Y.P., Song K.J., Wang C., Han Y.C. (1996). "Power flow analysis for a new isolation system flexible floating raft." Chinese Journal of Mechanical Engineering. $9,260-264$

24. Yang D. Q., Xie X. L., Chen W. (2012). "Laminate component method for hybrid structure optimal design on vibration reduction." Ships and Offshore Structures. 7(3), 321-332.

25. Yu L. B. (2007). "Research on Vibration Isolation Characteristics of the Floating Raft and Topology Optimization of Raft Body." Wuhan P.R.China. Huazhong University of Science and Technology.

\section{NOMENCLATURE}

AVLD: the acceleration vibration level difference, $\mathrm{AVLD}=20 \lg \left(\mathrm{a}_{\mathrm{A}} / \mathrm{a}_{\mathrm{B}}\right)$

$a_{A}, a_{B}:$ accelerations at point $\mathrm{A}$ and $\mathrm{B}$

$T_{s}$ : vector of thickness design variables for the components made of metal/steel.

$T_{c}$ : vector of thickness design variables for the components made of composite materials

$\tilde{\mathbf{X}}_{t}:$ vector of overall topology design variables defined by SIMP method

$\mathbf{X}_{i}=\left[x_{i 1} \cdot x_{i 2}, \cdots, x_{i}, \cdots x_{i T_{i}}\right]^{T}$ : vector of topology design variables for the $i$ th component, $x_{i t}$ is the topology design variable of element $t$ in component $i$.

$m$ : number of the composite components in hybrid structure $n:$ number of the metal/steel components

$T_{i}$ : total number of the finite elements in the $i$ th component $T_{i T}$ : total number of topology design variables in the $i$ th component

$\mathrm{se}_{i t}$ : area of the $i$ th element in the $i$ th component

$\rho_{s}, \rho_{c}$ : density of steel and composite materials.

$\sigma_{e k}$ : stress of the eth element under the $k t h$ loading case

$\sigma_{\mathrm{e}}^{L}, \sigma_{e}^{U}:$ lower and upper limit of element stress.

$\delta_{p k}, \bar{\delta}_{p}$ : displacement at point $\mathrm{p}$ under the kth loading case, upper limit of displacement at point $\mathrm{p}$.

$k$ : loading case number.

$a_{A j}^{\max }, a_{B j}^{\max }$ : maximum acceleration amplitude at point $\mathrm{A}$ and $\mathrm{B}$ in the frequency $j \mathrm{~Hz}$

$a_{A}^{U}, a_{B}^{U}$ : upper limit of the maximum acceleration amplitude at point $\mathrm{A}$ and $\mathrm{B}$

$L_{r}$ : lower limit of AVLD.

$f^{U}, f^{L}$ : upper and the lower bounds of frequency domain. 
$t_{i s}^{L}, \quad t_{i s}^{U}$ : upper and the lower bounds of the thickness design variables for metal/steel components.

$\varepsilon, s c a$ : relax parameter and equivalent scale of thickness for metal/steel and composite material

\section{CONTACT WITH THE AUTHOR}

Yinzhi Zhao

zhaoyz1982@126.com

School of Naval Architecture \& Ocean Engineering

Jiangsu University of Science and Technology

Zhenjiang, Jiangsu, 212003

CHINA 